\title{
REVISED Personal values influencing career path in academic
}

\section{medicine: Perspectives of selected Canadian trainees [version}

\section{2; peer review: 2 approved, 1 approved with reservations]}

Previously titled: Personal values influencing career path in academic medicine

\author{
Marissa Tsoi1 ${ }^{1}$ Braden D. Teitge2 ${ }^{2}$ Christopher R. Madan (iD) 3,4, \\ Louis H. Francescutti ${ }^{5}$ \\ ${ }^{1}$ Department of Family \& Community Medicine, University of Toronto, Toronto, Canada \\ ${ }^{2}$ Cumming School of Medicine, University of Calgary, Calgary, Canada \\ ${ }^{3}$ Department of Psychology, Boston College, Chestnut Hill, USA \\ ${ }^{4}$ School of Psychology, University of Nottingham, Nottingham, UK \\ ${ }^{5}$ School of Public Health, University of Alberta, Edmonton, Canada
}

V2 First published: 02 Aug 2016, 5:1903

https://doi.org/10.12688/f1000research.9026.1

Latest published: 25 Apr 2018, 5:1903

https://doi.org/10.12688/f1000research.9026.2

\section{Abstract}

To pursue research, education, and health policy in one's career, broadly defined as academic medicine, is one of the most important decisions of a trainee doctor's career. Despite this, there is scant literature on which factors influence trainees' choices towards clinical work or academic research. As the MD/PhD is a relatively young training path compared to the traditional PhD (Doctor of Philosophy) and MD (Doctor of Medicine) programs, it prompts the question: at the crossroads of a career, what sways the individual to select an MD, $\mathrm{PhD}$, or MD/PhD program? This is a valuable question to be answered for trainees who are considering multiple career paths, for educators who want to guide undifferentiated students, and for policy makers who develop and coordinate research programs. "Intellectual stimulation" is the most consistently identified personal value which draws trainees to academic medicine. Mentorship is linked strongly to success in the field. Conversely, long training periods, a lack of autonomy, and financial considerations are deterrents from a career in academic medicine. Insight into the decision-making process is provided by recent Canadian trainees in these respective fields, in a series of short interviews.

\section{Keywords}

medical education, academic medicine, personal values, MD/PhD, Canadian medical education, undergraduate medical education, postgraduate medical education, continuous medical education

\section{Open Peer Review}

\begin{tabular}{|c|c|c|c|}
\hline & 1 & 2 & 3 \\
\hline \multicolumn{4}{|l|}{ version 2} \\
\hline & & $\checkmark$ & $\checkmark$ \\
\hline 25 Apr 2018 & & view & view \\
\hline version 1 & $?$ & $?$ & \\
\hline 02 Aug 2016 & view & view & \\
\hline
\end{tabular}

1. Kirstie J. Whitaker, Alan Turing Institute, London, UK

2. Tobias C. Wood ID, King's College London $(\mathrm{KCL})$, London, UK

3. Jens Foell ID, Florida State University,

Tallahassee, USA

Any reports and responses or comments on the article can be found at the end of the article. 
Corresponding author: Braden D. Teitge (bradenteitge@gmail.com)

Author roles: Tsoi M: Investigation, Methodology, Writing - Original Draft Preparation, Writing - Review \& Editing; Teitge BD:

Conceptualization, Project Administration, Supervision, Writing - Review \& Editing; Madan CR: Conceptualization, Supervision, Writing Review \& Editing; Francescutti LH: Supervision, Writing - Review \& Editing

Competing interests: No competing interests were disclosed.

Grant information: The author(s) declared that no grants were involved in supporting this work.

Copyright: $\odot 2018$ Tsoi $\mathrm{M}$ et al. This is an open access article distributed under the terms of the Creative Commons Attribution License, which permits unrestricted use, distribution, and reproduction in any medium, provided the original work is properly cited. Data associated with the article are available under the terms of the Creative Commons Zero "No rights reserved" data waiver (CCO 1.0 Public domain dedication).

How to cite this article: Tsoi M, Teitge BD, Madan CR and Francescutti LH. Personal values influencing career path in academic medicine: Perspectives of selected Canadian trainees [version 2; peer review: $\mathbf{2}$ approved, 1 approved with reservations] F1000Research 2018, 5:1903 https://doi.org/10.12688/f1000research.9026.2

First published: 02 Aug 2016, 5:1903 https://doi.org/10.12688/f1000research.9026.1 


\section{REVISED Amendments from Version 1}

We would like to thank the reviewers for their time and expertise. We have addressed their concerns and changes are noted in the article.

The first reviewer notes that we are taking several common discussion points and addressing these in peer-reviewed literature. This article is not meant to be a large survey, but rather to address common discussion points. We feel that the personal values section provides an opinion in the background of a literature review. We acknowledge that this is a biased sample, and have put several qualifying statements in the text. Given the scope of this article, we are satisfied that this article will make a novel contribution to the literature.

The term "females" has been changed to "women" to recognize the reviewers point.

See referee reports

\section{What is academic medicine, where does it start, and who chooses it?}

Academic medicine is broadly defined as "the discovery and development of basic principles, effective policies, and best practices that advance research and education in the health sciences, ultimately to improve the health and well-being of individuals and populations"'. The interest in academic medicine comes from the fundamental tenet of modern medicine based on discovery, research and innovation. Physicians that are active in research and innovation help to keep medical knowledge and clinical care on the cutting edge, constantly improving and ensuring that we deliver the best care for our patients. Healthcare policy makers too must be familiar with health policy research to guide their decision-making and academic activity.

Encouraging the next generation of physicians to become active in research and health policy can only help the advancement of clinical care, from the bench to the bedside. Trainees may undertake academic medicine at several points in their career. Many obtain $\mathrm{MSc}$ or $\mathrm{PhD}$ degrees prior to enrolling in medical school; others enroll in a combined $\mathrm{MD} / \mathrm{PhD}$ program or complete a $\mathrm{PhD}$ degree during residency training; others yet decide later, as independent physicians, to add an academic component to their practice. Many residencies incorporate a strong academic aspect, especially for those completing fellowships in a sub-specialty.

With respect to the germination of this interest, it is recognized that research interest often begins in residency and medical school, with early exposure to research in medical school fostering interest in it as a career ${ }^{2}$. However, many factors determining career path are at play even earlier on, before the start of a graduate program or acceptance into a medical school. By virtue of entrance criteria, a decision whether to enter an MD or graduate program likely occurs around the time of undergraduate degree completion. Furthermore, it is interesting to examine the ongoing decision to remain in a chosen career pathway, for research has shown that trainees' interest in academic medicine wanes as they progress ${ }^{2}$.

Due to the various routes to a career in academic medicine, it is difficult to define distinct decision points in time when a trainee chooses to pursue academic medicine. Many extrinsic factors which influence career choice may vary over the course of this journey; this makes trainees' personal values relevant, if regarded as a consistent factor. Is there a type of individual who chooses academic medicine, and what values guide this person to an $\mathrm{MD}, \mathrm{MD} / \mathrm{PhD}$, or $\mathrm{PhD}$ degree?

The MD/PhD: a distinct avenue in academic medicine The MD/PhD combined degree is a clear and relatively modern pathway in structured academic medicine. Recent reductions in Canadian $\mathrm{MD} / \mathrm{PhD}$ funding cloud its future, but its historical rise has been promising. The first Canadian $\mathrm{MD} / \mathrm{PhD}$ program began in 1984 at the University of Toronto, with a starting class of 2 students. It has since grown to 42 students and is the largest program of its kind in Canada ${ }^{3}$. As of 2014, combined MD/PhD programs are offered at most medical schools in Canada ${ }^{4}$. The number of students accepted into a given school's $\mathrm{MD} / \mathrm{PhD}$ program each year varies between 1-10 across Canada, and interestingly the students are mostly men, in keeping with overall trends in academic medicine ${ }^{5}$.

The demand for clinicians with different expertise, such as education, health policy, or business has attracted trainees and educators to vastly grow the training programs that are now available. Trainees may now also pursue an MSc, MBA, or similar degree at nearly any point in their career. This allows physicians to combine clinical care with an interest in managerial skills, leadership, or virtually any interest complementary to medical practice. The expansion of these academic training pathways is changing the landscape of medical research and clinical care, prompting the question of which values guide trainees to choose academic careers, and what this means for the future of academic medicine.

Choosing academic medicine: pros, cons, and trends There is an array of literature on the current state of academic medicine in North America ${ }^{2}$. The most frequently cited disincentives are length of training, lower financial reward, and lack of autonomy ${ }^{6}$. The pressure to assume the "triple threat" mantle of clinical work, research, and education can also dissuade students from academia. Program length, fear of burnout, difficulty juggling work-life balance, and advanced age at completion are also reasons for dissatisfaction ${ }^{7}$. Of course, other factors such as debt and family influences also put pressure on the trainee to enter the workforce. Perhaps most concerning is that senior residents report less interest in research than junior residents over time ${ }^{7}$.

Academic training that comes in addition to a 3-4 year MD degree delays the trainee's potential professional level salaries. Until 2015, the Canadian Institutes of Health Research (CIHR) provided $\$ 21,000$ (CAD) of grant funding per annum for 6 years to $\mathrm{MD} / \mathrm{PhD}$ candidates $^{8}$. The average income 2 years after completing one's postdoctoral degree in Canada is $\$ 65,000^{\circ}$. One can attempt to compare this to a second-year MD resident's salary of roughly $\$ 60,000$, with a further substantial increase upon attaining a staff position at the end of residency ${ }^{10}$. Moreover, a standard MD degree takes at least 2-3 fewer years than either a $\mathrm{PhD}$ or an $\mathrm{MD} / \mathrm{PhD}$, therefore reducing time spent as a student.

Gender imbalance is a noted trend in academic medicine, as the overwhelming majority of those entering academics are 
men, and men in academic medicine have a greater salary. The salary difference between men and women is over $\$ 30,000$ for early-career physician-researchers despite adjustment for work hours, specialty, and academic rank ${ }^{11}$. This gender imbalance certainly needs to be addressed and rectified, both to encourage women to enter academic medicine, and to reward those that do make this decision. There are no robust studies examining the reasons for this, but a few cohort studies have shown that more women lose interest in research over time compared to $\operatorname{men}^{12}$ and that women in academia were less likely to be married than those in private practice ${ }^{13}$. A study with a focus group comprised of women found that perceived inflexibility in clinical pathways and decreased ability to balance competing roles were disincentives for academic medicine ${ }^{14}$.

Incentives drawing a trainee towards academic medicine include a passion for research, early exposure to research, desire to become an educator, desire for clinical appointment, and strong mentorship ${ }^{2}$. Most of the literature stresses that the earlier a trainee is involved in research and the more involved they are, the more likely they are to pursue academic medicine.

In terms of predicting who will enter and succeed in academic medicine, the strongest correlation is with the completion of a research fellowship or a degree such as a Masters, $\mathrm{PhD}$ or $\mathrm{MD} / \mathrm{PhD}^{15}$. A joint degree such as the $\mathrm{MD} / \mathrm{PhD}$ is often associated with faculty and academic appointment ${ }^{15}$. In a retrospective analysis of nearly 2000 medical graduates in the United States (1997-2002), those with a MD/PhD were more likely to have a full-time faculty appointment with an odds ratio of $2.33^{16}$. Publication of research conducted in medical school and residency correlated with trainees choosing academic medicine careers, as did attending a "research-intensive" university ${ }^{17,18}$.

Current trends in academic medicine include a shift of physicianscientists from laboratories to more clinical departments, and an increase in competency-based programs, which give researchers flexibility in combined programs such as the $\mathrm{MD} / \mathrm{PhD}^{7}$. In Canadian undergraduate medical education, there are numerous early academic tracks such as the MD with Special Training in Research (STiR, at the University of Alberta) and Research in Medicine (RiM, at Dalhousie University). These are aimed at cultivating an early academic interest in medical students. At the postgraduate level, there is the Clinician Investigator Program (CIP, at the Royal College of Physicians and Surgeons of Canada) for residents in sub-specialties, as well as the Clinician Scholars Program, offered by various medical schools across Canada, to both specialty and family medicine trainees.

\section{Values and the perspectives of individual trainees}

Borges et al. identified three divisions of values that influence the learner's decisions to pursue an academic career: the individual's personal values, the values of groups with which one associates, and generational values ${ }^{6}$. The only personal value consistently identified across studies was "intellectual stimulation" 19 . All other personal values leading to an academic career remain poorly defined ${ }^{6}$.
Meanwhile, Shea et al. identified characteristics of mentors and mentees that were deemed most important by a think tank of American physician-scientist programs. Personal attributes emerged at the top of both lists: for mentees the most crucial themes were passion, focus, ability to communicate clearly, desire, dedication, discipline, and resilience. For mentors the themes were prior mentoring successes, emotional intelligence, altruism, the will to promote independence, and optimism ${ }^{20}$.

The following narratives from medical trainees and practicing physician-researchers attempt to shed light on the individual's personal values and the thought processes which guide career decisions towards or away from academic medicine. The five interviews were conducted by either email or telephone correspondence, from January to May 2015. The interviews were conducted, transcribed, and summarized by a single interviewer. Questions were tailored to each participant, but a basis of core questions is shown in Table 2. The participants were selected from the authors' network of contacts to sample perspectives at each stage of academic medicine. All interviewees had completed some or all of their training at Canadian universities. The respondents consented to publication of their opinions, but were anonymized with respect to university, name, and location.

\section{Part 1: Considerations on prioritizing medical practice over research: the MD student perspective}

1.1: MD involved in research

This trainee stated that he enjoyed medical research, and found it was helpful to balance this with clinical work. He also wanted to work in an academic center, and found that a research background helped to open doors in major centers. He wanted research to be a distinct but relatively minor piece in his career, and did not feel the need to do additional training. Mentorship was also key, both in getting him initially involved in research and helping him navigate the waters of academia. This MD wanted to continue his involvement with research, because he enjoyed research, the mentorship, and the career opportunities it afforded him.

According to this trainee, the biggest draw to research right now is the competitive advantage it gives for academic career positions. In major teaching hospitals, many people now need some kind of research background, and the numerous fellowships are pushing more and more people into research. Keeping them involved however, is a bit more intensive, as we need to make sure that the infrastructure and grant support is there for our clinician researchers who are already very time constrained.

\section{2 - MSc prior to entering MD program}

This trainee stated that undergraduate experiences in research inspired her to attain a Masters degree, especially in a gap between undergraduate completion and application to medical school. She later chose to pursue an MD degree as she did not envision scientific research forming the major component of her career. The student was satisfied with continued research involvement while completing her medical degree. She had confidence at this stage with her research skills as a Masters graduate. Though open to consideration of a $\mathrm{PhD}$ in the future, she cited length of training and concerns over a possibly diminished quality of both clinical education and 
research as deterrents. In particular there was a concern due to the format of an $\mathrm{MD} / \mathrm{PhD}$ program, wherein gaps between the respective phases might lead to loss of clinical skills or, on the other hand, less novelty of one's research by training's end. This trainee personally preferred a singular focus on clinical practice as opposed to splitting her attention between that and academic medicine.

\section{Part 2: What an MD adds or takes away from PhD training: the $\mathrm{PhD}$ student perspective}

This trainee stated that prior to beginning his undergraduate program, he had planned to pursue an MD. As a means to gain useful experience as an undergraduate, he became involved in a research lab. However, through his undergraduate course work, he found that he did not enjoy some activities that he thought would be critical to being successful in medical school, memorizing anatomical nomenclature and dissection labs. Concurrently, he did find that he took well to research and was able to readily follow with the logical thinking and creative problem solving that are fundamental to academic research. This $\mathrm{PhD}$ student has since continued his research career as a postdoctoral research fellow, and plans to work towards a professor position at a research-intensive university. He commented that not having an MD and its related training have posed some limitations to his work, as he can not readily recruit patient populations without first finding an MD with relevant background and interests to collaborate with.

While he does not think that everyone interested in obtaining an $\mathrm{MD}$ would be better suited with a $\mathrm{MD} / \mathrm{PhD}$, he does think that scientific literacy is an important skill for MDs, and that becoming involved in a research laboratory at the undergraduate level should be encouraged for students considering a medical career, even if just in volunteer capacity. Exposure to academia may make future doctors more readily able to incorporate scientific advances into their practice.

\section{Part 3: Balancing practice and research: the MD/PhD student perspective}

This student chose the MD/PhD path because of the inspiring early undergraduate research experience she was involved with. These experiences ranged from volunteering in a laboratory doing benchwork, to interacting with patients in clinic. When she had a gap between undergraduate completion and application to medical school, her strong $\mathrm{MD} / \mathrm{PhD}$ mentors, including the Program Director, guided her towards academic medicine.

In terms of personal values, this trainee had a strong sense of social justice and felt that her research was emotionally as well as intellectually stimulating. She felt that her attempts to effect large-scale change would be eased by having the $\mathrm{MD} / \mathrm{PhD}$ degree. This was a way for her opinions to carry more weight, which would strengthen her ability to advocate for her patient population. As someone who was planning to spend half her future career in research and half in clinical duties, she was overall very well suited to her program.

Regarding the gender divide, she noted that although numbers were equal for men and women early in the program she found fewer mentors who were women on the tenure track and at academic conferences. Another personal value in her decision was her relatively young age at entry to the program. She felt that the $\mathrm{MD} / \mathrm{PhD}$ path gave her more time to decide what field of medicine to devote herself to, and this was time she could afford.

\section{Part 4: Practicing MD returns to pursue a PhD: the lifelong-learner perspective}

This experienced physician felt that his practice situation, at a community health centre, had stabilized over the years thanks to a team of seasoned colleagues. Now was a good time to ease up on clinical commitments and pursue a $\mathrm{PhD}$ in philosophy. From a personal perspective, he reflected on returning to academia having something to do with his time of life. He wished to continue intellectual challenges, broadening his understanding and knowledge, as well as analytic and argument skills. As he serves a low socioeconomic status population, he felt he could improve his value as a resource with this formal training in philosophy - by advocating more effectively. He cited his belief that we need to ask ourselves honestly what we owe one another in this world, a broad question that could not be answered within the narrow confines of medical practice. He envisioned teaching, mentoring and modeling a more pervasive and broadly-informed understanding of philosophy, morals and values as applied to the healthcare and other systems. He wished to place particular emphasis on a more complex and complete understanding of marginalized populations, and of the role of the physician in society. In seeing how society treats its marginalized sections, as well as many years of coming up against healthcare's attitudes toward disadvantaged populations, he was convinced of the necessity to ask questions in a different way. $\mathrm{A} \mathrm{PhD} \mathrm{in}$ philosophy would help this physician formulate those questions to be more clear, meaningful, and effective.

\section{Discussion}

While these are only a handful of individuals' perspectives, in aggregate they provide insight into the considerations involved in pursing academic medicine, as well as the benefits of formal research training to medical practice. Each of these trainees pursued further academic training at different times in their careers, drawn to academia by a passion for research, critical thinking, social justice and the influence this would have on their career path (Table 1). Similarly, many trainees also felt that time duration and financial constraints were drawbacks of pursuing research. This is extremely relevant now, given the recent funding changes in the Canadian Institute of Health Research for MD/PhD programs. Namely, as of

Table 1. Perceived draws and deterrents related to a career in academic medicine.

\begin{tabular}{|l|l|}
\hline Draws of academic medicine & $\begin{array}{l}\text { Deterrents from } \\
\text { academic medicine }\end{array}$ \\
\hline Passion for research & Prolonged training \\
\hline Desire to educate & Lower income \\
\hline Impact of a strong mentor & Reduced autonomy \\
\hline $\begin{array}{l}\text { Desire for academic } \\
\text { appointment }\end{array}$ & Family considerations \\
\hline
\end{tabular}


Table 2. Core questions posed in email and telephone interviews with participants.

1. Why did you choose to pursue an $\mathrm{MD}, \mathrm{MD} / \mathrm{PhD}$ or $\mathrm{PhD}$ at this stage?

2. What were some personal values going into this decision?

3. What further academic (either research or education) career do you envision for yourself? Will your ongoing/future practice be purely clinical, purely research-centred, or a blend of both?

4. Can you comment on the impact of mentors (either positive or negative) towards your decision to get an MD vs an MD/PhD vs PhD?

5. Are you satisfied with your current degree of academic involvement?

6. Do you feel that your university/work environment is a highly-supportive culture for academia? Do you consider it "renowned" for academics, and did that influence your decision to get your MD vs MD/PhD vs PhD?

7. Were financial reasons part of why you decided to be an MD vs PhD vs MD/PhD? What about length of program/time constraints?

8. (If applicable): do you have any thoughts on being female and the career decisions you have made towards or away from academia?

2016, the CIHR has discontinued funding of their thirty-year old $\mathrm{MD} / \mathrm{PhD}$ studentship program, in universities across Canada ${ }^{21}$. Though an $\mathrm{MD} / \mathrm{PhD}$ is not for everyone, it is unfortunate that this program has been cancelled, likely resulting in a decrease in crossover between medical practice and research. Undoubtedly, the $\mathrm{MD} / \mathrm{PhD}$ programs in Canada cannot continue as they were before.

Funding matters aside, there is an interesting gender difference in terms of academic medicine engagement. Multiple studies and focus groups have tried to characterize the values and reasons behind the relative lack of trainees and mentors who are women in academic medicine ${ }^{11-14}$. This warrants further attention as women likely share the same personal values as their colleagues who are men, that will draw them to academic medicine, yet additional deterrents have been identified within this group.

\section{Conclusion}

The personal values that draw one to academic medicine can be used to improve recruitment to academic programs. More research is needed on definition and classification of these personal values, but "intellectual stimulation" is the most consistently identified. Trainees that have a passion for research and academic advancement can be encouraged along this path by identifying them and pairing them with a strong mentor early in their careers. All trainees emphasized the value of mentorship in academia, and its foundation in making or breaking a career in research. Alternatively, we should also be aware of the very real deterrents that are turning away qualified trainees. Long training periods, a lack of autonomy, and financial considerations were identified as deterrents from a career in academic medicine. Being aware of these perceived barriers allows policy makers to address them and help to recruit the best trainees through modification of existing programs.

At a time when the public's knowledge of basic science and fundamental medicine is lagging relative to the rapid development of medical science, technology, and social policy ${ }^{22}$, those who pursue academic medicine will be the essential communicators who bridge the gap. It is paramount that these individuals and groups are identified, supported and lauded for their intellectual thirst. Understanding the personal values and constellation of factors which help an individual decide on a career in academic medicine will hopefully streamline access to academic positions which suit the trainee. This in turn will likely produce medical, scientific, and health policy advancements which will efficiently shorten the "knowledge translation" gap. Overall, this bodes well for patient care at the individual level and for society at large.

\section{Author contributions}

Dr. Marissa Tsoi was the primary author of this work, and conducted the literature search and interviews. She guided the overall vision of this article and was responsible for writing it at all stages. Dr. Braden Teitge and Dr. Christopher Madan conceived the idea of the paper and were responsible for all subsequent edits. Dr. Teitge also helped to coordinate the process of collaboration and formatting. Dr. Louis Francescutti provided guidance on the article's overall concept.

\section{Competing interests}

No competing interests were disclosed.

\section{Grant information}

The author(s) declared that no grants were involved in supporting this work.

\section{Acknowledgments}

The authors would like to acknowledge the contributions of all the interviewees, and Dr. Matthew Rose from the University of Alberta for his contribution, guidance, and feedback on this article. 
1. Academic Medicine. Royal College of Physicians. London, United Kingdom; [Accessed January 2, 2016]. Reference Source

2. Straus SE, Straus $\mathrm{C}$, Tzanetos $\mathrm{K}$, et al.: Career choice in academic medicine: systematic review. J Gen Intern Med. 2006; 21(12): 1222-9.

PubMed Abstract | Publisher Full Text | Free Full Text

3. History of the MD/PhD program. University of Toronto. Toronto, Ontario; [Accessed January 2, 2016]. Reference Source

4. Admission requirements of Canadian Faculties of Medicine: admission in 2014. The Association of Faculties of Medicine of Canada. Ottawa, Ontario; [Accessed January 2, 2016].

Reference Source

5. Jagsi R, Guancial EA, Worobey CC, et al:: The "gender gap" in authorship of academic medical literature--a 35-year perspective. N Engl J Med. 2006; 355(3): 281-7.

PubMed Abstract | Publisher Full Text

6. Borges NJ, Navarro AM, Grover A, et al:: How, when, and why do physicians choose careers in academic medicine? A literature review. Acad Med. 2010; 85(4): 680-6. PubMed Abstract | Publisher Full Text

7. Ballios BG, Rosenblum ND: Challenges facing physician scientist trainees: a survey of trainees in Canada's largest undergraduate and postgraduate programs in a single centre. Clin Invest Med. 2014; 37(5): E268-83. PubMed Abstract | Publisher Full Text

8. Funding Opportunity Details (MD/PhD Students, 2014-2015). ResearchNet. Public Works and Government Services Canada. Ottawa, ON; 2016. [Accessed January 2, 2016]. Reference Source

9. Desjardins L, King D: Expectations and labour market outcomes of doctoral graduates from Canadian universities. Culture, Tourism and the Centre for Education Statistics. Statistics Canada, Human Resources and Skills Development Canada. Ottawa, Ontario; 2016. [Accessed January 2, 2016]. Reference Source

10. 2013-2016 PARO-CAHO agreement. Professional Association of Residents of Ontario. Toronto, Ontario; 2016. [Accessed January 2, 2016]. Reference Source

11. Jagsi $R$, Griffith $K A$, Stewart $A$, et al.: Gender differences in salary in a recent cohort of early-career physician-researchers. Acad Med. 2013; 88(11): 1689-99. PubMed Abstract | Publisher Full Text | Free Full Text

12. Leonard JC, Ellsbury KE: Gender and interest in academic careers among first- and third-year residents. Acad Med. 1996; 71(5): 502-4. PubMed Abstract | Publisher Full Text

13. Reiser LW, Sledge WH, Fenton W, et al.: Beginning careers in academic psychiatry for women--"Bermuda Triangle"? Am J Psychiatry. 1993; 150(9): 1392-7. PubMed Abstract | Publisher Full Text

14. Brown AJ, Swinyard W, Ogle J: Women in academic medicine: a report of focus groups and questionnaires, with conjoint analysis. $J$ Womens Health (Larchmt). 2003; 12(10): 999-1008.

PubMed Abstract | Publisher Full Text

15. Fang D, Meyer RE: Effect of two Howard Hughes Medical Institute research training programs for medical students on the likelihood of pursuing research careers. Acad Med. 2003; 78(12): 1271-80. PubMed Abstract | Publisher Full Text

16. Andriole DA, Jeffe DB, Hageman HL, et al:: Variables associated with full-time faculty appointment among contemporary U.S. Medical school graduates: implications for academic medicine workforce diversity. Acad Med. 2010; 85(7): 1250-7.

PubMed Abstract | Publisher Full Text | Free Full Text

17. Feng $L$, Ruzai-Shaprio C: Factors that influence radiologists' career choices. Acad Radiol. 2003; 10(1): 45-51. PubMed Abstract | Publisher Full Text

18. Neacy K, Stern SA, Kim HM, et al:: Resident perception of academic skills training and impact on academic career choice. Acad Emerg Med. 2000; 7(12): 1408-15.

PubMed Abstract | Publisher Full Text

19. Wyrzykowski AD, Han E, Pettitt BJ, et al:: A profile of female academic surgeons: training, credentials, and academic success. Am Surg. 2006; 72(12): 1153-9; discussion 1158-9.

PubMed Abstract

20. Shea JA, Stern DT, Klotman PE, et al.: Career development of physician scientists: a survey of leaders in academic medicine. Am J Med. 2011; 124(8): 779-87.

PubMed Abstract | Publisher Full Text

21. Silverman $\mathrm{M}$ : Cutting funds for $\mathrm{MD} / \mathrm{PhD}$ programs a blow to Canadian innovation. The Globe and Mail. 2015; Accessed February 1, 2016. Reference Source

22. Morris ZS, Wooding $\mathrm{S}$, Grant $\mathrm{J}$ : The answer is $\mathbf{1 7}$ years, what is the question: understanding time lags in translational research. $J$ R Soc Med. 2011; 104(12): 510-520.

PubMed Abstract | Publisher Full Text | Free Full Text 


\section{Open Peer Review}

\section{Current Peer Review Status:}

\section{Version 2}

Reviewer Report 10 August 2018

https://doi.org/10.5256/f1000research.16068.r36944

(C) 2018 Foell J. This is an open access peer review report distributed under the terms of the Creative Commons Attribution License, which permits unrestricted use, distribution, and reproduction in any medium, provided the original work is properly cited.

\section{Jens Foell \\ Department of Psychology, Florida State University, Tallahassee, FL, USA}

The presented article is a summary of current findings regarding the driving factors in deciding to pursue MD training, PhD training, or both. Based on findings in the cited literature, the article discusses a psychological drive for intellectual stimulation, together with available mentorship, as the most consistent drivers of these decisions. Examples for different career paths are presented, based on interviews that the authors have conducted. All of this is presented from a Canadian / North American perspective.

The article is very well written and the topic is timely and should be interesting and useful to a large number of readers. While the article is very good as it is, I would like to raise a few discussion points in the hope that they might improve the manuscript further:

1. As mentioned above, the presented information is given in the context of the Canadian / North American system and the authors make this clear at several points in the text (as well as in the title) so as not to create any confusion. However, for a reader outside of this region, it might be useful to know that much of the information given in the text might be different for them: not all countries offer combined MD/PhD career paths, and/or the interplay between clinical work and research might be structured differently. Similarly, funding structures differ between countries, and the decision to go in a specific direction might have to be made earlier or in a different context than in the given examples. I don't think that all of this needs to be described here, as it would distract from the main points of the text, but I think it would be useful to mention, either in a footnote or in the Discussion section, that the influence of personal values as described here might conceivably be different in an international context, where other/additional influential factors might be at play.

2. I very much appreciate the authors addressing the gender imbalance in academia, which is certainly an influencing factor on individual career decisions. This is similar to the situation for people with a low socioeconomic background or those belonging to an underrepresented minority (URM). Now, it is not my intent to dilute the very important discussion of gender issues by introducing another topic that will then compete for the 
reader's attention. However, it does feel that its omission makes the article miss an important additional influential factor of career paths and decisions, especially since discouragement is being discussed. My recommendation would be to mention this topic in a footnote or in the discussion section, making the point that, similar to the mentioned gender imbalance, belonging to an URM or coming from a non-academic or lowsocioeconomic background can present a filter, limiting one's actual or perceived options regarding academic career paths. These filters might not act in the same way, to the same degree, or at the same entry points as the mentioned gender imbalance, and they might not have been studied to the same degree. Nevertheless, they might interact with the mentioned deterrents to limit options and to otherwise impede the decision-making process.

3. A minor note: it is mentioned that women in academia are less likely to be married than those in private practice (citation 13). Were they also less likely to be married than men in comparable positions? I assume this is the case; either way it might be an interesting addition to this sentence, maybe in parentheses or as a footnote.

Thank you very much for writing this important and interesting article.

Is the topic of the opinion article discussed accurately in the context of the current literature?

Yes

Are all factual statements correct and adequately supported by citations? Yes

Are arguments sufficiently supported by evidence from the published literature? Yes

Are the conclusions drawn balanced and justified on the basis of the presented arguments? Yes

Competing Interests: No competing interests were disclosed.

I confirm that I have read this submission and believe that I have an appropriate level of expertise to confirm that it is of an acceptable scientific standard.

Reviewer Report 09 May 2018

https://doi.org/10.5256/f1000research.16068.r33426

(C) 2018 Wood T. This is an open access peer review report distributed under the terms of the Creative Commons Attribution License, which permits unrestricted use, distribution, and reproduction in any medium, provided the original work is properly cited.

Tobias C. Wood 
Department of Neuroimaging, Institute of Psychiatry, Psychology \& Neuroscience (IoPPN), King's College London (KCL), London, UK

I have no further comments.

Is the topic of the opinion article discussed accurately in the context of the current literature?

Yes

Are all factual statements correct and adequately supported by citations? Yes

Are arguments sufficiently supported by evidence from the published literature? Yes

Are the conclusions drawn balanced and justified on the basis of the presented arguments? Yes

Competing Interests: No competing interests were disclosed.

I confirm that I have read this submission and believe that I have an appropriate level of expertise to confirm that it is of an acceptable scientific standard.

\section{Version 1}

Reviewer Report 27 February 2017

\section{https://doi.org/10.5256/f1000research.9710.r20199}

(C) 2017 Wood T. This is an open access peer review report distributed under the terms of the Creative Commons Attribution License, which permits unrestricted use, distribution, and reproduction in any medium, provided the original work is properly cited.

\section{Tobias C. Wood}

Department of Neuroimaging, Institute of Psychiatry, Psychology \& Neuroscience (IoPPN), King's College London (KCL), London, UK

This opinion article consists of two parts.

The first is a thorough literature review. It gives a solid overview of the issues surrounding the MD/PhD program. I have no issues with this section.

The second part consists of five transcribed interviews, and I consider it weaker than the first section. The evidence presented is only anecdotal, with a very small sample size. The author states that the interviewees were drawn from the author's academic contacts, so although a range of 
views and backgrounds is represented, sample bias cannot be excluded. Given that this an opinion and not a full research article this is not a reason for rejection, but this section could be greatly strengthened with additional interviews, ideally from outside the author's network. Alternatively, given the length of time that has elapsed since the original interviews, follow-up interviews checking whether the participants still felt the same way about their courses would be enlightening.

The discussion and conclusion sections are mostly good. However, the second paragraph of the discussion contains the following sentence: "Multiple studies and focus groups have tried to characterize the values and reasons behind the relative lack of female trainees and mentors in academic medicine.", but no citations are given. I suspect that the authors are correct in this assertion, but a relevant citation or other evidence to back up this statement must be added before indexing.

Is the topic of the opinion article discussed accurately in the context of the current literature?

Yes

Are all factual statements correct and adequately supported by citations? Yes

Are arguments sufficiently supported by evidence from the published literature? Yes

Are the conclusions drawn balanced and justified on the basis of the presented arguments? Yes

Competing Interests: No competing interests were disclosed.

I confirm that I have read this submission and believe that I have an appropriate level of expertise to confirm that it is of an acceptable scientific standard, however I have significant reservations, as outlined above.

Reviewer Report 24 February 2017

https://doi.org/10.5256/f1000research.9710.r20201

(C) 2017 Whitaker K. This is an open access peer review report distributed under the terms of the Creative Commons Attribution License, which permits unrestricted use, distribution, and reproduction in any medium, provided the original work is properly cited.

Kirstie J. Whitaker

Alan Turing Institute, London, UK

Synopsis

Tsoi and colleagues start with a definition of academic medicine and a summary of this career 
path and who chooses to take it. They then explain the pros and cons of academic medicine as have been described in the currently published literature. Finally, they present summaries of interviews conducted with five medical professionals: two MD students, one PhD student, one MD/PhD student and one experienced clinician (MD) who has returned to complete a PhD at an advanced stage of his career.

\section{Compliments}

It is important for personal motivations and values to be included in our understanding of career paths in all aspects of science and medicine. This article has the potential to take "common knowledge" and hearsay and put it into a peer-reviewed literature. It makes these discussions findable and citable: important steps towards progressing our understanding of addressing structural inequalities in career progression. This work stands to benefit many readers who are interested in careers in academic medical but are looking for more detailed information on the prospect.

\section{Concerns/Suggestions}

\section{Audience}

Who is the intended audience for this opinion piece? The abstract mentions trainees, educators and policy makers, and the authors are right that this topic is of interest to all these groups. Unfortunately, the focus for each of them are quite different and I think the paper fails to provide succinct take home messages for any of them. (Alternatively, this is a qualitative research article and should be structured as such, see my comments below).

I'd recommend developing the discussion section and potentially including actions that interested parties may take as a result of the findings presented in the paper. To be clear: my recommendation is to restructure the opinion article, as there is a lot of useful advice/information included in the introduction that I think could be put to better use supporting the research findings, rather than add in more information to the discussion.

\section{Integrating personal values}

The introduction to this opinion article outlines most of the arguments for/against a career in academic medicine so the summaries of the interviews do not end up providing much new information to the reader. If the point of the article is to present personal values, I'd recommend integrating quotes from the interview subjects along with the background literature. Although not necessary, I suspect that arranging the information around themes rather than by individual participant would synthesise the findings more effectively. Qualitative research is not my area of expertise but I enjoyed these suggestions from London School of Economics (which includes links to further reading on the topic).

\section{Missing voices}

There are key demographics who are not interviewed in this article on the career path in academic medicine: specifically, those of clinicians who do not see the benefits of it and/or who those who were not able to continue along this path. Furthermore, all people interviewed are students which leaves out most of the time spent along this career path. This is fine, but I'd like the authors to acknowledge that they are presenting a biased sample which may limit its generalisability for readers considering a career in academic medicine.

Related to this point, and more minor in my opinion, is that this article seems to be written about academic medicine careers in Canada. I'd recommend that the authors clarify this focus in the abstract and either acknowledge that these findings may not be relevant to clinicians in other 
countries or develop the breadth of the introduction and discussion to consider these differences.

Females

Please do not refer to adult women as "females". The use of this adjective as a noun reduces women to their reproductive abilities and diminishes their humanity (see Jezebel for my favourite article on the subject). I'm confident that this was not the authors' intention, but given that a focus of this opinion article is the reasons women are not well represented within academic medicine, $I^{\prime} d$ advise avoiding further alienation. I'd recommend referring to women and men (rather than males) as appropriate.

Is the topic of the opinion article discussed accurately in the context of the current literature?

Yes

Are all factual statements correct and adequately supported by citations?

Yes

Are arguments sufficiently supported by evidence from the published literature? Yes

Are the conclusions drawn balanced and justified on the basis of the presented arguments? Yes

Competing Interests: No competing interests were disclosed.

I confirm that I have read this submission and believe that I have an appropriate level of expertise to confirm that it is of an acceptable scientific standard, however I have significant reservations, as outlined above.

\section{Comments on this article}

\section{Version 1}

Reader Comment 10 Apr 2018

William Phillips, University of Washington, Seattle, USA

Building on personal values, we have developed an innovative model for learner-centered mentoring that can be particularly valuable for early career researchers.

Phillips WR. Pursuing personal passion: Learner-centered research mentoring. Family Medicine. 2018; 50:7. https://doi.org/10.22454/FamMed.2018.952474

Competing Interests: No competing interests were disclosed. 
The benefits of publishing with F1000Research:

- Your article is published within days, with no editorial bias

- You can publish traditional articles, null/negative results, case reports, data notes and more

- The peer review process is transparent and collaborative

- Your article is indexed in PubMed after passing peer review

- Dedicated customer support at every stage

For pre-submission enquiries, contact research@f1000.com 